Gauss reversal. Either three plate pairs separated faster before and slower after this reversal or, as Wilson asserts, the age of the reversal is 10 to $20 \mathrm{kyr}$ younger than indicated in the new timescales ${ }^{3,4}$. It is unclear how these small differences can be independently resolved with available techniques.

If one accepts the implication that plate motions are very steady over the past several million years, it is natural to ask how true this is over briefer timescales. The expanding data from space geodesy, mainly from very-long-baseline interferometry (VLBI) and satellite laser ranging (SLR), place strong constraints on plate velocities averaged over the past several to dozen years $^{7-9}$ and are similar to velocities calculated from the NUVEL-1 global model of plate velocities averaged over the past approximately $3 \mathrm{Myr}$ (ref. 10). The correlation coefficient between space geodetic and NUVEL-1 rates is 0.994 , but the space geodetic rates are slower by $6 \pm 1$ per cent (see figure) ${ }^{11}$. The new timescale ${ }^{5}$ indicates that the ages assumed in calibrating NUVEL-1 were about 4.5 per cent too young, so it gives velocities 4.5 per cent too fast, which leaves a marginally significant differ-

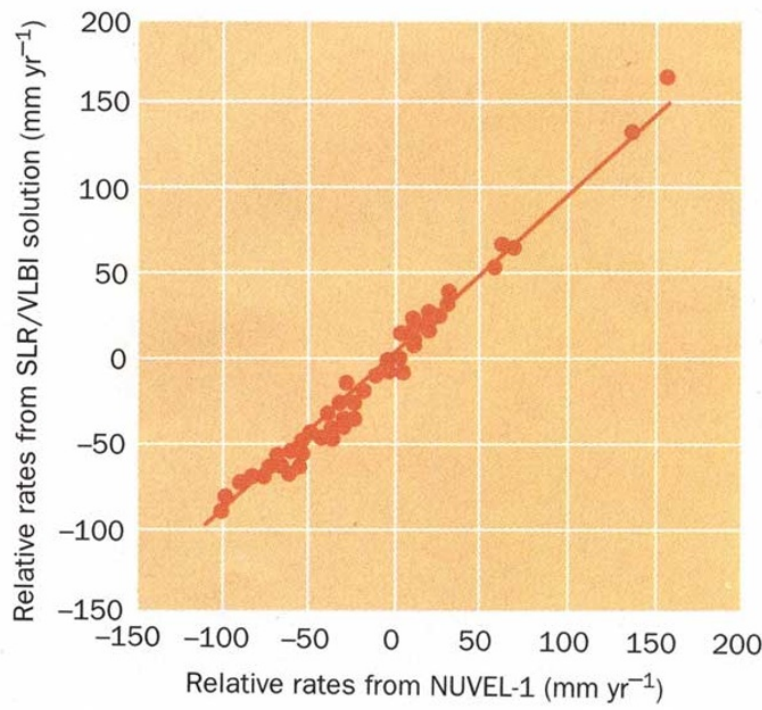

Correlation plot showing how closely the plate motion rates derived from space geodesy, averaged over about 4 to 12 years, compare with rates averaged over about 3 Myr. Space geodetic results are based on 149 lines between 20 sites far from plate boundaries. After ref. 11 .

ence of about 1.5 per cent between platetectonic rates averaged over years and those averaged over millions of years. There are many possible explanations for this small remaining difference.

The implications of the combined results from precise estimates of sea-floor spreading, the revised geomagnetic reversal timescale and space geodesy indicate that plate motions are very steady, to within a few per cent, over a timescale that ranges from several years to several millions of years. Steady motion of plate interiors may seem surprising in light of the episodic motion associated with earthquakes at plate boundaries. However, outside the zone of elastic strain accumulation surrounding locked faults between earthquakes, the steadiness is an expected consequence of the dynamic equilibrium of driving forces (buoyancy forces and pressure gradients) with viscous resistive forces in the highly damped convective system of the solid Earth. The driving forces of a tectonic plate, and hence its velocity, are expected to be constant in so far as the geometry and thermal structure of a plate, its boundary, and any attached subducted slab are unchanged.

Wilson's work places tentative limits on how long steady motion persists, as several plate pairs have been steady within 3 per cent or less for intervals of 2 to $4 \mathrm{Myr}$ (possibly longer in one case). Similar analyses of other plate pairs could take this further, and might place limits on how quickly plate velocities readjust during their apparently infrequent accelerations. Studies of marine magnetic anomalies cannot, however, tell us the shortest interval over which plate motions are steady. Perhaps continuous monitoring of plate

motions using Global Positioning System geodesy will eventually determine whether plates move steadily at timescales even shorter than several years, as would be expected from our understanding of the physics of plate motion.

Richard G. Gordon is in the Laboratoire de Géodynamique Sous-Marine, B.P. 48, 06230 Villefranche sur Mer, France, on leave from the Department of Geological Sciences, Northwestern University, Evan-

2. Vogt. P. R. in The Geology of North America, Vol. M, The Western North Atlantic Region (eds Vogt, P. R. \& Tucholke, B. E.) 405-425 (The Geological Society of America, Boulder, 1986)

3. Shackleton, N. J., Berger, A. \& Peltier, W. R. Trans. $R$ Soc. Edin.: Earth Sci. 81, 251-261 (1990)

4. Hilgen, F. J. Earth planet. Sci. Lett. 104, 226-244 (1991)

5. Hilgen, F. J. Earth planet. Sci. Lett. 107, 349 (1991)

6. Baksi, A. K. Hsu, V. McWilliams, M. O \& Farrar, E. Science 256. 356-357 (1992).

7. Clark. T. A. etal. J. geophys. Res. 92, 12741-12750 (1987)

8. Argus, D. F. \& Gordon, R. G. J. geophys. Res. 95 17315-17324(1990)

9. Smith. D. E. etal. J. geophys. Res. 95, 22013-22041 (1990)

10 DeMets, C., Gordon, R. G. Argus, D. F. \& Stein, S. Geophys. J. int 101, 425-478(1990).

11. Robbins, J.W., Smith, D. E. \& Ma, C. Crustal Dynamics (American Geophysical Union, Washington DC, in the press) ston, Illinois 60208, USA.

1. Wilson, D. S. Nature 364, 788-790 (1993)

\section{Ancestral arthropod}

A FossIL arthropod from the Silurian (about 420 million years ago) of Australia may represent a transitional form between myriapods and insects (K. J. NcNamara and N. H. Trewin, Palaeontology 36, 319$335 ; 1993)$. The animal, named Kalbarria brimmellae, was about $120 \mathrm{~mm}$ long, had a poorly demarcated head, a thoracic region loosely regionated into mono-, diplo- and triplosegments and bearing 11 pairs of legs, and an appendage-free abdomen. Kalbarria is a euthycarcinoid, a group of arthropods known only from fossils of Upper Carboniferous and Middle Triassic age. Although a close relationship with insects has been proposed, fully evolved winged insects were in evidence by the Lower Carboniferous. But Kalbarria lived 120 million years earlier than the previous earliest-known example of its group, so it is possible that insects evolved from a myriapod-like ancestor via something that looked like a euthycarcinoid.

\section{Strength to strength}

IN 1990, the Japanese firm of Kobe Steel Ltd developed a carbon steel wire with a tensile strength of some $5 \mathrm{GPa}$, well above the previous limit of about $3 \mathrm{GPa}$. Why this remarkable increase? H. K. D. H. Bhadeshia and $\mathrm{H}$. Harada may have found the answer (Appl. Surf. Sci. 67, 328-333; 1993). Using field ion microscopy, they found that the severe deformation during manufacture produces a very fine structure of dislocation cells in the wire, and also forces much of the carbon in the steel into solid solution. Both effects hamper the movement and growth of dislocations - narrow defect regions in the crystal lattice - in the wire, so that macroscopic yielding is triggered only at higher loads. The wire makes excellent fishing line - so will 'the one that got away' now be $70 \%$ larger than before?

\section{Sticks and stones}

ELEPHANTS are arguably the most frequent mammalian tool-users after humans and chimpanzees. Just as in primates, tool use is not a single, stereotyped kind of behaviour but an adjunct to a wide range of activities which together reflect the animals' adaptive needs (S. ChevalierSkolnikoff and J. Liska, Anim. Behav. 46, 201-219; 1993). So whereas small, vulnerable cebid monkeys use tools in aggressive displays, elephants tend to use them to keep cool (squirting mud or water on themselves) or free from parasites (using the trunk to handle sticks or grasses to scratch itches or swat flies). Aggression (brandishing branches or throwing rocks) is less important. The authors speculate that the need for artificial aids to personal hygiene is keenly felt in large, furless tropical land mammals.

In last week's Résumé, the reference for the final item is Appl. Phys. Lett. 63, 15-17; 1993. 